DOSSIÊ

\title{
A discussão de políticas educacionais no interior da escola: resistência e naturalização
}

\author{
Elita Betania de Andrade Martins
}

\section{RESUMO}

O texto traz elementos que ajudam a compreender como os professores da educação básica têm discutido as políticas educacionais. Para isso, apresenta dados de uma pesquisa cujo objetivo foi identificar possíveis transformações nas práticas docentes e gestoras, reconhecidas por eles como decorrentes das atuais políticas educacionais. Contou com o aporte teórico de autores como Ball (2005, 2008), Fairclough (2016), Mainardes (2006), entre outros, para caracterizar o contexto macro das políticas e o micro, por meio da percepção de professores e gestores. Os resultados indicaram poucos momentos coletivos, nos quais mais acontecem explanações que discussões sobre as políticas educacionais, e, ainda, a necessidade do fortalecimento de redes de comunicação que favoreçam leituras e interpretações resistentes para reflexão sobre o processo de comoditização educacional e de naturalização de valores da cultura empresarial.

PALAVRAS-CHAVE

políticas educacionais; escola; professores.

'Universidade Federal de Juiz de Fora, Juiz de Fora, MG, Brasil. 


\section{THE DISCUSSION OF EDUCATIONAL POLICIES WITHIN THE SCHOOL: RESISTANCE AND NATURALIZATION}

\section{ABSTRACT}

The text brings elements that help to understand how teachers of basic education have discussed educational policies. For this, it presents data from a research whose objective was to identify possible changes in teaching and management practices, recognized by them as resulting from current educational policies. It had the theoretical support of authors such as Ball (2005, 2008), Fairclough (2016), Mainardes (2006), among others, to characterize the macro and micro context of policies, through the perception of teachers and managers. The results indicated few collective moments, in which more explanations happen than discussions about educational policies and the need to strengthen communication networks that favor resistant readings and interpretations to reflect on the process of educational commoditization and the naturalization of values of corporate culture.

KEYWORDS

educational policies; school; teachers.

\section{LA DISCUSIÓN DE LAS POLÍTICAS EDUCATIVAS DENTRO DE LA ESCUELA: RESISTENCIA Y NATURALIZACIÓN}

\section{RESUMEN}

E1 texto trae elementos que ayudan a comprender cómo los docentes de educación básica han discutido las políticas educativas. Para eso, presenta datos de una investigación cuyo objetivo era identificar posibles cambios en las prácticas de enseñanza y gestión, reconocidas por ellos como resultado de las políticas educativas actuales. Contaba con el apoyo teórico de autores como Ball (2005, 2008), Fairclough (2016), Mainardes (2006), entre otros, para caracterizar el contexto macro y micro de las políticas, a través de la percepción de docentes y directivos. Los resultados indicaron pocos momentos colectivos, en los que ocurren más explicaciones que discusiones sobre políticas educativas, lo que evidencia la necesidad de fortalecer las redes de comunicación que favorecen las lecturas e interpretaciones resistentes para reflexionar sobre el proceso de mercantilización educativa y la naturalización de los valores de la cultura.

PALABRAS CLAVE

políticas educativas; escuela; profesores. 


\section{INTRODUÇÃO}

O presente texto tem por finalidade apresentar alguns elementos que ajudam a compreender como os professores de escolas públicas de educação básica têm discutido as políticas educacionais no interior da escola. Tal estudo é parte de uma pesquisa cujo objetivo foi identificar possíveis transformações nas práticas docentes e gestoras reconhecidas pelos professores e gestores da rede pública de Minas Gerais como decorrentes das atuais políticas educacionais.

Inicialmente, fazemos algumas considerações no tocante ao contexto político atual, para, em seguida, apresentarmos informações quanto ao desenvolvimento da pesquisa, dados obtidos, sobre como e quais temas têm sido alvo das atenções dos professores nas discussões realizadas nas escolas.

Há, ainda, a indicação da necessidade de ações que possam contribuir para o debate de algumas ideias que, associadas a uma lógica de mercado, parecem estar sendo naturalizadas no contexto escolar.

\section{O CONTEXTO: ALGUNS ELEMENTOS}

Desde 2016, o Brasil passa por um processo de crise econômica e política, com a adoção de medidas não democráticas, as quais desagradam parcela significativa da população, por poderem resultar em perda de direitos e agravamento das condições de vida, sobretudo dos setores populares, tais como a Emenda Constitucional $\mathrm{n}^{\circ}$ 95/2016 ${ }^{1}$, a aprovação da reforma trabalhista e o projeto de reforma previdenciária.

$\mathrm{Na}$ área educacional, os desafios não são menores. Em 2016, por meio da Medida Provisória (MP) no 746/2016, que originou a Lei no 13.415/2017, foi aprovada a reorganização do ensino médio, sob o discurso de criação de um currículo mais flexível e de valorização da autonomia do discente, para que possa escolher seu percurso formativo. Tal reforma, criticada por não ter dado continuidade ao debate sobre ensino médio, já presente na Câmara, e por não incluir na discussão os atores diretamente envolvidos, foi marcada pela preocupação em atender às demandas econômicas do mercado. O então secretário de Educação Rossieli Soares da Silva justificou a reforma ser feita por MP, porque seria necessário "fazer a máquina girar":

Que a nossa população de jovens será menor do que a nossa população de idosos, o peso vai ser maior, de novo, para a previdência. $\mathrm{E}$ o movimento da nossa economia precisa do jovem trabalhador, que faz a máquina girar, precisa do jovem empreendedor que vai criar e gerar riqueza para o país, para que o país seja sustentável. Se a gente não mexer nisso com urgência, para gente poder gerar um efeito para 2018,2019, se não fosse por MP teríamos que assumir que a reforma do ensino médio não é importante. (apud Mapa Educação, 2016)

1 Limita, por 20 anos, os gastos públicos e estabelece que o governo federal só poderá aumentar suas despesas de acordo com a inflação acumulada conforme o Índice de Preços ao Consumidor (IPCA). 
Diretamente ligada à reforma do ensino médio, a aprovação da Base Nacional Comum Curricular (BNCC) foi marcada por rupturas. Iniciado em 2015, com a apresentação de um documento preliminar, com o qual se abria uma consulta pública, possibilitando o envio de sugestões individuais ou de instituições públicas e privadas, o processo teve sua condução alterada, com a mudança da equipe responsável pelas discussões (em virtude do afastamento da presidente e das modificações do ministério) e separou a discussão da proposta de BNCC para o ensino médio das demais etapas da educação básica, o que recebeu várias críticas.

Ainda em 2016, houve alteração na composição do Conselho Nacional de Educação, pelo decreto de 27 de junho de 2016, que invalidou a nomeação feita pela ex-presidente Dilma Rousseff e indicou novos membros vinculados ao setor educacional privado, fato que foi duramente criticado pela Confederação Nacional dos Trabalhadores em Estabelecimentos de Ensino (Contee) (Sinpro, 2016).

A indicação de representantes desse setor está ligada à "enorme expansão da participação do setor privado na educação pública” (Rosa, 2013, p. 460), como parte do que o autor chama de fase pós-neoliberal. Nessa nova fase, cresce a crença na importância da participação de novos fornecedores e gestores de serviços públicos e o Estado passa a ser valorizado como um criador de mercados, favorecendo, regulando e monitorando as ações da iniciativa privada.

Esse movimento, que é internacional, conforme indica o próprio Ball (apud Rosa, 2013), tem se materializado no Brasil não só com a presença de representantes do setor privado em conselhos e órgãos ligados ao governo, mas também mediante a ação de organizações como o Movimento Brasil Competitivo (MBC), mantido por empresas como a Gerdau, a Fiat, a Eurofarma, a Natura, entre outras, que se associaram à Secretaria de Educação de Pernambuco, para o desenvolvimento do Programa Gestão de Resultados, programa considerado pelo então ministro da Educação Mendonça Filho como modelo para reorganização do ensino médio, no que se refere à implantação do tempo integral.

A atuação de representantes da iniciativa privada de diversos setores na área da educação contribui para o que Dardot e Laval (2016) trataram como a criação de uma nova subjetividade, uma maneira de ser, "de conceber a si mesmo e comportar-se como uma empresa”(Dardot e Laval, 2016, p. 17) necessária ao modelo neoliberal. Nas palavras dos referidos autores, "o neoliberalismo pode ser definido como o conjunto de discursos, práticas e dispositivos que determinam um novo modo de governo dos homens segundo o princípio universal da concorrência"(Dardot e Laval, 2016, p.17).

Destacam ainda que, para seu desenvolvimento e a criação de tal subjetividade, a racionalidade neoliberal pode se ligar a ideologias estranhas à pura lógica mercantil, sem, entretanto, perder seu domínio, exemplificando com o modelo dos Estados Unidos, onde ideias neoliberais e neoconservadoras de teor altamente moralizador se associam. Dardot e Laval (2016) enfatizam que, apesar da aparente "discordância",

entre neoliberalismo e neoconservadorismo existe uma concordância que não é nada fortuita: se a racionalidade neoliberal eleva a empresa a modelo de subjetivação, é simplesmente porque a forma-empresa é a "forma celular" de moralização do indivíduo trabalhador, do mesmo modo que a família é a "forma celular" da moralização da criança. (Dardot e Laval, 2016, p. 388) 
A aliança entre o pensamento neoliberal e o neoconservador no Brasil pode ser ilustrada por meio da ação de movimentos como o Escola sem Partido. Difundido desde 2004, com a atuação do advogado Miguel Nagib, tal movimento, segundo Silveira (2019), é inspirado por ideias disseminadas nos Estados Unidos de combate ao que eles classificavam como doutrinação nas escolas.

Os defensores do Escola sem Partido ampliam gradativamente seu espaço na opinião pública e têm cada vez mais forte influência nas assembleias legislativas municipais, estaduais e no próprio Congresso Nacional. Entre outras ideias, apresentam uma concepção de escolarização que nega o papel de educador ao professor, por dissociarem educação e instrução. Conforme Penna (2017), para os defensores de tal pensamento, "o ato de educar seria responsabilidade da família e da religião; então o professor teria que se limitar a instruir” (Penna, 2017, p. 36).

$\mathrm{Na}$ concepção desse movimento, o professor é um técnico que não pode se reportar a noticiários ou abordar temas que possam estar em desacordo com os valores familiares dos alunos, sob o risco de ser considerado um doutrinador. $\mathrm{O}$ conhecimento, então, passa a ser tratado como algo a ser empacotado.

Essa lógica, como nos adverte Severino (2011), é uma das consequências desse modelo que atrela à educação a lógica de desenvolvimento econômico inspirado em critérios mercadológicos:

O sistema subverte ainda a lógica do conhecimento, eliminando seu processamento como construção dos objetos conhecidos. Torna-se mero produto, e não mais processo, experiência de criatividade, de criticidade e de competência. É literalmente tecnificado, objetivado, empacotado. (Severino, 2011, p. 8)

O professor, então, tratado como um técnico que entrega o conhecimento empacotado, a cada dia se sente menos valorizado e pressionado pelas ideias de movimentos como o Escola sem Partido, as quais, mesmo tendo sido consideradas pelo Ministério Público Federal (MPF) como inconstitucionais (Cristaldo, 2016), têm conseguido obter o que Ramos (2017) classificou como "consentimento ativo dos cidadãos”. Estes assumem como neutros os princípios do movimento Escola sem Partido e acabam incorporando um conjunto de crenças que reforçam o domínio da classe dirigente. A incorporação dessas crenças contribui para "gerar um clima de assédio moral no interior da escola e de toda a sociedade" (Ramos, 2017, p. 84).

Esse clima de controle e de tensão pode também se agravar com a pressão das avaliações externas. Tais avaliações passam a exercer outro tipo de influência sobre o trabalho docente, muitas vezes estabelecendo aquilo a que o professor se reportará para saber como organizar seu trabalho, com vistas a alcançar os resultados esperados, os quais, por sua vez, passam a ser quantificados. Essa subordinação à produção de resultados em avaliações, fruto das reformas educacionais implantadas, traz consequências na concepção de profissionalismo docente, já que o professor passa a ser considerado com base no "desempenho (performance), em que o que conta como prática profissional resume-se a satisfazer julgamentos fixos e impostos a partir de fora" (Ball, 2005, p. 542). 
Essas, entre outras questões, despertaram nosso interesse em conhecer como os professores da educação básica lidavam com esses assuntos no seu cotidiano: tinham consciência e tratavam dessas questões no interior da escola? Percebiam a sua influência no seu trabalho diário? Para isso, desenvolvemos a pesquisa intitulada Que educação para que país, sobre a qual apresentamos alguns elementos, especialmente aqueles ligados à discussão das políticas públicas no interior das escolas e que, em nossa compreensão, reforçam a necessidade de fortalecer as articulações entre associações de pesquisa, universidades e escolas de educação básica.

\section{A PESQUISA: SEU DESENVOLVIMENTO}

Para estudar tais questões, o Grupo de Estudo em Sistemas de Ensino (Gese) da Universidade Federal de Juiz de Fora (UFJF) partiu da compreensão de que pesquisar políticas públicas em educação pressupõe reconhecer que elas resultam de um jogo de forças presentes em um contexto histórico, social, econômico e cultural com suas intencionalidades. Para isso, baseamo-nos em autores como Stephen Ball, o qual destaca a importância, tanto da análise do nível macro do sistema educacional, as políticas educacionais, quanto da pesquisa do nível micro, considerando as experiências e as percepções das pessoas.

Ball (2008) considera que políticas são tanto processos quanto resultados e distingue o que chamou política como texto da política como discurso. Para ele, os textos são o produto de compromissos que vão se constituindo, desde a influência inicial, passando pela formulação legislativa, pelos processos parlamentares e influência de grupos políticos nos vários estágios em suas articulações. Assim, chega à ideia da importância de analisar a trajetória das políticas, dadas as diferentes interpretações que vão recebendo em todo o processo.

Com base nessa concepção, realizamos o presente estudo, o qual teve como objetivo identificar possíveis transformações nas práticas docentes e gestoras, reconhecidas pelos professores e gestores da rede pública de Minas Gerais como decorrentes das atuais políticas educacionais.

A pesquisa, de cunho quantiqualitativo, utilizou como recursos metodológicos, além da análise de documentos e legislações, questionários e entrevistas, os quais foram analisados com base nas contribuições da análise de discurso (Fairclough, 2016).

Para o seu desenvolvimento ${ }^{2}$, foram selecionadas quatro escolas públicas (duas pertencentes à rede estadual e duas à rede municipal de Juiz de Fora), pela combinação: número de alunos, resultado no Índice de Desenvolvimento da Educação Básica (Ideb) ${ }^{3}$ e localização.

2 A partir de 2017, contou com apoio da Fundação de Amparo à Pesquisa do Estado de Minas Gerais (Fapemig).

3 Criado em 2007 e calculado com base no fluxo escolar e nas médias de desempenho em avaliações como o Sistema de Avaliação da Educação Básica (Saeb) e a Prova Brasil. 
O questionário, semiestruturado, respondido voluntariamente por professores e gestores das escolas pesquisadas, apresentava 26 questões, as quais permitiram traçar um perfil dos respondentes e, ainda, que os professores expressassem seu conhecimento e sua opinião sobre as atuais políticas educacionais.

Vale ressaltar que a aplicação dos questionários aconteceu durante momentos coletivos das escolas, conforme a direção de cada unidade avaliou ser mais adequado, entretanto tivemos mais dificuldades de retorno dos questionários nas escolas com menor Ideb, o que pode indicar maior resistência dos professores dessas escolas em participar da pesquisa. Porém, não podemos desconsiderar que os poucos momentos coletivos, além do recreio, também tenham interferido nesse processo de devolução dos questionários, principalmente nas escolas maiores, e que pareceu igualmente impactar nas discussões sobre políticas educacionais, como vemos mais adiante.

Com isso, obtivemos 80 questionários, que foram analisados com auxílio do aplicativo Google Forms e de tabelas elaboradas pelo grupo, fornecendo dados que possibilitaram a organização das entrevistas.

Para a etapa de entrevistas, buscamos professores em situações extremas de experiência profissional: com muito tempo de atuação e com o menor tempo de atuação entre os que eram lotados em cada escola — um aspecto importante, não apenas para contextualizar melhor a história de cada unidade escolar, como também observar possíveis diferenças na compreensão sobre as atuais políticas educacionais.

Além dos professores, buscamos entrevistar os diretores, entretanto em uma das escolas pesquisadas a diretora preferiu não participar, alegando estar havia pouco tempo no cargo e indicando a coordenadora, que anteriormente ocupou a função por vários anos. Assim, foram realizadas 12 entrevistas (três profissionais por escola), com sujeitos que possuíam experiência profissional variando de 2 a 28 anos de magistério.

Após a sua transcrição, as entrevistas foram organizadas em quadros e analisadas por categorias relacionadas aos objetivos específicos do estudo. Podemos destacar entre as categorias:

- Condições de trabalho, que, segundo Hypolito (2012), envolve elementos indissociáveis, como formação, carreira, remuneração, formas de contratação, processo de trabalho, condições físicas e materiais;

- Currículo, na qual se fizeram presentes as discussões sobre a BNCC;

- Planejamento, englobando desde o projeto político-pedagógico da escola ao Plano Nacional de Educação (PNE);

- Avaliações externas e Ideb.

A análise dos dados baseou-se em informações obtidas nas entrevistas, assim como nos questionários, relacionando-as às categorias anteriormente apresentadas, e fundamentou-se nas contribuições teóricas de Ball e Bowe (apud Mainardes, 2006) sobre o ciclo de políticas, no qual se devem considerar três contextos (o de influência, o de produção e o da prática), os quais se inter-relacionam, mas não são lineares e apresentam, em cada um deles, arenas de disputas e embates de diferentes grupos.

Segundo Ball (2008), em todos os estágios do processo político, os textos são interpretados e reinterpretados pelos diferentes sujeitos do contexto. Assim, ao 
atuarmos com os professores que estão no contexto da prática das políticas educacionais, que é onde, conforme o referido autor, a política produz efeitos e consequências, mas também é sujeita a ser reinterpretada e a sofrer mudanças significativas em relação à original, podemos conhecer um pouco dessas reinterpretações dadas pelos docentes. A afirmação de Mainardes, com base nas contribuições de Ball e Bowe, reforça nosso pensamento:

Esta abordagem, portanto, assume que os professores e demais profissionais exercem um papel ativo no processo de interpretação e reinterpretação das políticas educacionais e, dessa forma, o que eles pensam e no que acreditam têm implicações para o processo de implementação das políticas. (Mainardes, 2006, p. 53 , grifos nossos)

Assim, é necessário conhecer o que os professores têm discutido e pensado, identificar discursos que se fazem presentes na escola. Para isso, contamos com as contribuições de Fairclough (2016), o qual destaca que discurso envolve diferentes tipos de linguagens, de relações e se modifica por contextos e/ou sujeitos. Os discursos não só refletem ou representam relações sociais e entidades, mas constroem-nas, fazendo com que diversos pesquisadores se dediquem a estudar mudanças sociais, constituídas nas mudanças das práticas de linguagem. A construção de discursos que reforçam ou modificam determinadas práticas sociais nos ajuda a compreender possíveis releituras de políticas desenvolvidas, sobretudo no contexto de prática, sinalizado por Ball (2008).

Fairclough (2016), em seus estudos, identificou algumas tendências de mudanças discursivas que afetam os discursos e tendem a mudanças mais gerais do ponto de vista social e cultural, entre as quais a comoditização. Tal expressão foi utilizada pelo autor para designar

o processo pelo qual os domínios e as instituições sociais, cujo propósito não seja produzir mercadorias (commodities) no sentido econômico restrito de artigos para venda, vêm não obstante a ser organizados e definidos em termos de produção, distribuição e consumo de mercadorias. (Fairclough, 2016, p. 265)

Assim, a escola, instituição educacional que não teria como finalidade a produção de mercadorias, passa a empregar discursos marcados por expressões originárias de instituições voltadas para demandas comerciais, tais como mercado educacional, alunos clientes, empreendedorismo, habilidade e competência, pacotes de conhecimentos, treinamento etc. O processo de comoditização, aliado ao gênero publicitário, tem contribuído para a constituição de identidades sociais e, do ponto de vista ideológico, é muito eficaz quando se naturaliza, tornando senso comum.

Porém Fairclough (2016) alerta que, na análise da prática discursiva, é importante se considerar a intertextualidade, propriedade que têm os textos ${ }^{4}$ de serem

4 Texto é considerado pelo autor como uma dimensão do discurso, como o produto escrito ou falado. 
cheios de fragmentos de outros textos. Essa intertextualidade, às vezes, é manifesta, sendo claramente dito que é composto de outros textos e, em outros momentos, não. Além disso, nem sempre essa interseção de textos apresenta coerência interna.

Para o autor, existem intérpretes de textos mais submissos e outros mais resistentes. Ele destaca a importância de leituras resistentes:

As interpretações resistentes são um modo de luta hegemônica quanto à articulação dos elementos intertextuais. Embora elas tipicamente levem a processos de produção textual que projetam a luta hegemônica em formas mais explícitas, isso nem sempre ocorre, e é importante levar em consideração as formas pelas quais os intérpretes interpretam os textos, para que se possa avaliar adequadamente sua eficácia política e ideológica. (Fairclough, 2016, p. 180)

Para que um sujeito possa fazer essa leitura resistente, destrinchando a coerência interna de textos, será necessário levar em conta a posição que ocupa em uma relação social e, além disso, um conjunto de elementos e de informações que dispõe para fazer as conexões e inferências necessárias ao processo de interpretação e reinterpretação das políticas educacionais. Daí, indagamos: como os professores têm lido e construído os discursos que circulam no interior da escola e se apropriado deles? A seguir, apresentamos algumas das informações obtidas.

\section{O QUE DIZEM OS PROFESSORES?}

Como indicamos anteriormente, o objetivo da pesquisa era identificar possíveis transformações ocorridas nas práticas docentes e gestoras reconhecidas pelos professores e gestores como decorrentes das políticas educacionais, mas, para compreender as respostas obtidas, é necessário caracterizar os participantes.

Com base nos questionários, foi possível observar que a maioria dos participantes da pesquisa tem mais de 30 anos de idade (57,5\% de 30 a 44 anos e $32,5 \%$ mais de 45 anos) e é um grupo com significativa experiência profissional: 15\% tem de quatro a sete anos de serviço; 33,8\%, de oito a 15 anos; e 23,85\%, de 16 a 25 anos.

Todos são devidamente habilitados para o exercício da profissão: $52,5 \%$ possui especialização, $15 \%$ mestrado e $5 \%$ doutorado.

A maioria é efetiva no cargo em que atua $(58,8 \%)$, entretanto o número de contratados é expressivo (33,8\%). Vale destacar que o status de efetivo parece ser algo recente, pois, quando questionados sobre o tempo de exercício na função atual, $15 \%$ declarou até um ano e $22,5 \%$ de um a três anos. Tal quadro pode estar ligado a um fato ocorrido na rede estadual de Minas Gerais, que ficou conhecido como Lei 100.

Em 2007, na gestão de Aécio Neves (Partido da Social Democracia Brasileira — PSDB), para regularizar a situação previdenciária de trabalhadores da Secretaria Estadual de Educação, o governo criou a Lei Complementar estadual no 100/2007, reconhecendo, sem concurso público, tais trabalhadores como efetivados, o que gerou muitas incertezas, processos judiciais e, em 2014, resultou em declaração de inconstitucionalidade pelo Supremo Tribunal Federal (STF). 
Assim, em 2015, na gestão de Fernando Pimentel (Partido dos Trabalhadores - PT), esses trabalhadores efetivados tiveram de deixar os cargos para que os aprovados em concurso público pudessem assumir. Tal situação criou clima de tensão nas escolas, muitas das quais tiveram praticamente todo o seu quadro profissional alterado, como foi o caso da Escola $\mathrm{EA}^{5}$, conforme revelado pela diretora, em entrevista:

Entrevistada: Mudou muito de 2015 pra 2016, foi o ano que a gente assumiu a direção.

Entrevistadora: Em virtude dessa Lei 100 ou não?

Entrevistada: Porque, assim, muitos que estavam aqui, inclusive que nos ajudaram a conseguir chegar na direção, que eram, assim, nossos apoiadores, saíram da escola. Perderam o cargo. Então, a gente recebeu muita gente novata de 2015 pra cá. [...] Então, assim, foi um período muito conturbado 2016. As pessoas que saíram ficaram muito revoltadas, né?!

Entrevistadora: E hoje você tem um número maior de professores efetivos ou não?

Entrevistada: É, praticamente 90\% dos professores são efetivos. Quem não é efetivo na escola tá substituindo alguém. (Diretora A, Escola EA, maio 2018, grifos nossos)

Enquanto nas escolas da rede estadual há um grande número de professores efetivos, nas escolas da rede municipal a realidade é outra. $O$ último concurso realizado para preenchimento de cargos docentes ocorreu no ano de 2008, havendo a previsão de realização de concurso para o segundo semestre de 2018 (Nocelli, 2018), o que até a presente data não se efetivou.

Após os dados de caracterização do perfil dos respondentes, os questionários apresentavam questões abordando temas das políticas públicas educacionais, para que os professores se posicionassem. No presente texto, destacamos algumas das questões analisadas.

A questão 3.1 era: "Sobre as atuais políticas educacionais, você se considera", para a qual $70 \%$ dos respondentes se declararam razoavelmente informados. Apesar de a maioria se considerar razoavelmente informada, os professores entendem que as políticas educacionais não têm contribuído $(37,5 \%)$ ou têm contribuído em parte para a qualidade da educação (70\%).

Ao fundamentarem suas respostas, os professores apresentavam nas justificativas para a afirmação "em parte" argumentos que revelam uma avaliação negativa e insatisfação com as políticas educacionais, tais como: "Muito focado na teoria" (EEA 003); "Porque as políticas educacionais seja de forma de cima para baixo, sem ampla discussão com

5 Atribuímos letras para designar as escolas e os profissionais, sem nenhuma ordem hierárquica, apenas para garantir o anonimato das instituições e dos participantes. 
a comunidade escolar" (EEA 018); "Para serem eficazes, as politicas educacionais precisam da atuação de todos os envolvidos na educação, principalmente dos nossos governos" (EEH 019); "Falta de empenho e interesse no desenvolvimento da educação" (EMJ 007); "Algumas mudanças nas politicas educacionais não atingem seus objetivos iniciais” (EMR 014).

O item 3.5 do questionário era: "Quais das atuais políticas educacionais têm sido alvo de discussões na escola?". Entre as alternativas apresentadas ${ }^{6}$, quatro tiveram maior frequência de escolha: avaliação externa (70\%); lei do piso (67,5\%); reforma do ensino médio (57,5\%); e plano de carreira (55\%).

A respeito desses temas, fazemos breves considerações que nos ajudam a refletir sobre as discussões acerca da política educacional no interior da escola.

\section{AVALIAÇÃO EXTERNA}

As respostas ao questionário indicaram que as avaliações externas influenciam $(37,5 \%)$ ou influenciam em parte $(32,5 \%)$ o planejamento pedagógico. Tal influência talvez seja consequência do que Bonamino e Sousa (2012) classificaram como segunda e terceira geração das avaliações educacionais em larga escala. Essas denominações foram utilizadas para se referir a momentos nos quais no país é feita a divulgação de resultados das avaliações à comunidade, vinculada à responsabilização de professores e adoção de mecanismos de sanção ou recompensas.

Afirmaram, ainda, desenvolverem ações voltadas para a melhoria do Ideb, porém quase metade dos respondentes (48,75\%) não informou a medida adotada pela escola, o que é um importante dado, pois pode representar certa forma de resistência docente aos impactos dessa política, mas também sugerir desconhecimento sobre as ações desenvolvidas, já que as respostas apontaram não haver debate ou estudo coletivo sobre o tema, como tratamos ao abordar a discussão sobre políticas educacionais. Entre as ações mencionadas, podemos destacar: revisão da prática pedagógica, desenvolvimento de projetos, adaptação das avaliações e ampliação da jornada.

As entrevistas também sinalizaram pouca discussão sobre avaliações externas na escola, especialmente acerca do Ideb, como pode ser observado nos trechos a seguir:

Entrevistadora: [...] Você tinha notícia ou em algum momento alguém conversou com você sobre o Ideb da escola? Sobre o resultado da escola?

Entrevistada: Não.

Entrevistadora: Isso aparece em alguma reunião? É um assunto que preocupa os professores?

Entrevistada: Até o exato momento, não. Que eu me lembre, [nome da pesquisadora], não!

Entrevistadora: Uhum. Não é algo que "ah, vamos parar e conversar sobre o Ideb da escola"?

6 É necessário esclarecer que poderia ser escolhida mais de uma alternativa. 
Entrevistada: Não, não. (Professora T, Escola MJ, set. 2018)

Há, ainda, a sinalização de, quando tratado, acontecer de forma rápida, no sentido de tomar conhecimento:

Entrevistadora: E com relação ao Ideb, a escola reflete sobre seu Ideb? E assim... Tem alguma ação específica em relação ao índice do Ideb?

Entrevistada: Tem, por exemplo... Tem assim... Os momentos que têm reuniões, aí já aproveita para passar para falar. Pra ver o que pode ser melhorado para esse próximo... Nesse sentido. Não para pra isso. (Professora P, Escola $\mathrm{EH}$, ago. 2018, grifos nossos)

Entrevistadora: [...] Como que é o Ideb da escola? Isso é conversado aqui na escola?

Entrevistada: O Ideb é... Ideb é até razoável, não sei te precisar para você nota $\mathrm{X}$, mas tem o Ideb, é razoável.

Entrevistadora: Mas tem uma reunião que se discute...

Entrevistada: Fala, fala, no começo do ano ela mostra, não sei se ainda está pregado ali fora. (Professora M, Escola EA, maio 2018, grifos nossos)

Cabe esclarecer que a professora $\mathrm{M}$, ao afirmar "pregado ali fora", refere-se a uma prática que foi adotada nas escolas estaduais de Minas Gerais até 2014. Sob orientação da Secretaria Estadual de Educação, era divulgado para a comunidade, em uma placa próxima ao portão da escola, o resultado obtido no Ideb, em uma espécie de prestação de contas. Apesar de essa prática não ser mantida pelo grupo que assumiu o governo mineiro em 2015, a Escola EA, que há anos obtém resultados acima da média, ainda mantém a placa.

A influência dos órgãos centrais de educação na forma como a questão da avaliação é tratada também se revela na fala do vice-diretor da Escola MJ. Segundo $\mathrm{V}$, nas reuniões pedagógicas, às vezes se trata sobre o Ideb, porque "tem uma orientação na Secretaria de Educação pra olhar o Ideb e repassar para os professores. Se não fosse isso, não teria...”. Ele faz tal afirmação por acreditar que os professores, por diversas razões, não têm interesse sobre o tema.

\section{LEI DO PISO E PLANO DE CARREIRA}

A Lei Federal no 11.738/2008, conhecida como Lei do Piso, instituiu um valor mínimo de remuneração a ser pago aos professores em todo o país. Além disso, estabeleceu que $1 / 3$ da carga horária docente deve ser reservado às atividades extraclasse, tais como capacitação, planejamento, correção de atividades, reuniões, entre outras (Brasil, 2008).

Apesar de representar importante conquista do magistério, a resposta dos professores indicou que ela não é bem compreendida.Para $66,2 \%$ dos respondentes, 
não houve nenhuma mudança na organização escolar decorrente da aprovação da referida lei.

Os professores participantes da pesquisa, tanto da rede municipal como da rede estadual, não identificam que a organização de seu tempo de trabalho atual esteja ligada à observância dessa lei.

$\mathrm{Na}$ rede municipal, os professores são contratados para uma carga horária de 20 horas, sendo 13 horas e 20 minutos para regência e o restante do tempo para atividades extraclasse, não necessariamente cumpridas dentro da escola. $\mathrm{Na}$ rede estadual, os professores são contratados para uma carga horária de 24 horas, das quais 16 horas são destinadas à regência e as 8 horas restantes divididas para atividades extraclasse, exercidas dentro e fora da escola.

Nem mesmo o efeito da lei, no sentido de assegurar o piso salarial nacional, é identificado pelos professores e isso foi bandeira de paralisações e greves que aconteceram nas duas redes de ensino, nos anos de 2017 e 2018. Os professores criticam a interpretação dada ao primeiro parágrafo do artigo $2^{\circ}$ da lei, que estabelece:

O piso salarial profissional nacional é o valor abaixo do qual a União, os Estados, o Distrito Federal e os Municípios não poderão fixar o vencimento inicial das Carreiras do magistério público da educação básica, para a jornada de, no máximo, 40 (quarenta) horas semanais. (Brasil, 2008, grifo nosso)

Segundo o governo e juristas, o valor refere-se a uma carga horária de 40 horas. Portanto, se o professor trabalha 20 horas, deverá ser feita a proporção. Já os sindicalistas e a categoria docente, de modo geral, entendem que é o valor mínimo a ser pago e que eventuais acréscimos poderiam ser feitos em caso de cargas horárias superiores, não ultrapassando 40 horas semanais.

Esse impasse gera muita insatisfação e dúvidas, conforme revelaram as entrevistas:

Entrevistada: Olha, a lei do piso eu já não sei mais nada, porque uns falam que Pimentel cumpre a lei do piso, outros falam que não. Eu acho até que ele cumpre, porque o piso não é 40 horas? O piso que fala, na lei federal, é 40 horas. Então eu acho até que ele cumpre. (Professora M., Escola EA, maio 2018)

Entrevistadora: [...] E lei do piso, o que você já ouviu falar sobre a lei do piso?

Entrevistada: Bem, que, com nosso piso, pelo que eu trabalho, eu não recebo o piso. Recebo proporcional. (Professora T, Escola MJ, set. 2018)

As falas indicam uma compreensão da lei do piso apenas no sentido de garantia de valores de remuneração, o que, muitas vezes, é visto como algo distante de ser cumprido, pelo fato de estar ligado ao plano de carreira, quarto tema eleito pelos professores entre os mais discutidos e que também tem sido motivo de preocupações, como pode ser observado a seguir:

Entrevistadora: Você já ouviu falar sobre a lei do piso? 
Entrevistada: A lei do piso nacional?

Entrevistadora: Isso. Você acredita que sua rede tem seguido essa lei do piso? Você acha que está seguindo?

Entrevistada: Se a gente está recebendo essa lei do piso?

Entrevistadora: Isso.

Entrevistada: Não, eu acho que esteja não.

Entrevistadora: Essa é uma discussão e tanto, né? Falam que pagam o piso, mas muita gente não considera que é pago.

Entrevistada: É... Eu não considero. Aliás, a gente não está nem recebendo! [risos]. (Professora P, Escola EH, ago. 2018)

Vale considerar que a reforma trabalhista, aprovada em 2017, gerou muitas incertezas e o quadro apresentado pela mídia de crise financeira nos estados, entre os quais Minas Gerais está incluído, sinalizava possibilidade de alterações no plano de carreira do magistério e de perda de direitos.

A professora $\mathrm{P}$ denuncia o parcelamento de salários feito pelo governo estadual, alegando falta de recursos. Essa situação gerou nos professores da rede estadual muito desânimo e sentimento de desvalorização, como demonstrado pela professora $\mathrm{D}$, ao tratar do escalonamento:

Foi fracionado. Então, era para dividir em três parcelas, quem recebia até três mil reais, recebia uma parcela única, quem recebia três até seis, duas parcelas, e acima disso três. Só que ele [governo] fracionou a primeira parcela. [...] Todo mundo tem compromisso, e você arcar com despesa, o governo não paga para você os juros que você tá pagando. [...] Então, assim, tá complicado! Estamos levando, tão levando. (Professora D, Escola EH, ago. 2018)

A ideia de ir "levando" revela o desânimo docente, de lutar continuamente por remuneração adequada, sem conseguir o retorno esperado, o que parece criar certa acomodação. Os depoimentos a seguir ilustram tal desânimo:

Entrevistada: O não cumprimento da lei [referindo-se à lei do piso], nem tanto porque assim, a gente tá acostu... Mas, assim, o que interfere é esse fato de ele não pagar o dia, ter essa divisão. Isso aí interfere, porque isso te deixa apreensiva, a gente não sabe que data, não sabe quando, você tem conta para pagar. (Professora P, Escola EH, ago. 2018)

Durante a entrevista, a diretora A relata o fato de a lei do piso ser uma das pautas da última greve de professores da rede estadual e a desmotivação dos docentes com os resultados do movimento. 
Entrevistadora: Essa foi uma das pautas da última greve, a lei do piso, e aí, quando a greve terminou, os professores conseguiram avanços ou voltaram desanimados?

Entrevistada: Voltaram desanimados. Voltaram desanimados!

Entrevistadora: Uhum.

Entrevistada: E muitos ficaram assim "parou pra quê? Se não resolveu nada". (Diretora A, Escola EA, maio 2018)

Já o relato do diretor $\mathrm{B}$ sobre o fato de professores aceitarem, muitas vezes, um contrato com a intenção de conseguir ampliar a experiência profissional no currículo, como um diferencial em futuras contratações ou concursos, apesar dos baixos salários, exemplifica o que anteriormente denominamos de acomodação:

Entrevistado: [...] Então, o professor tem que encabeçar bem, quando a gente abre aqui um processo de contratação de uma semana ou duas, aí vem 10, 15 pessoas que às vezes vai pagar nem o transporte.

Entrevistadora: Porque é pouco tempo...

Entrevistado: Pouco tempo, mora longe, pega dois ônibus, tem alimentação.

Entrevistadora: Mas pega para acumular o tempo?

Entrevistado: Também viu, assim, aonde tá seco o que pingar tá bom, não é? (Diretor B, Escola EH, ago. 2018, grifos nossos)

A perda de direitos na rede estadual não está vinculada apenas à garantia do pagamento do piso ou à incerteza de recebimento do próprio salário, mas também a questões como licenças remuneradas para cursos de aperfeiçoamento, que, apesar de previstas no plano de carreira do estado, estão suspensas. A diretora $\mathrm{A}$, ao relatar sua dificuldade em combinar carga horária de trabalho e tempo para formação, trata desse tema:

Entrevistada: $\mathrm{O}$ tempo não tem como eu dedicar para estudar, não tem jeito.

Entrevistadora: E quando você estava como professora, aliás, como coordenadora, como era isso? Você conseguia?

Entrevistada: Conseguia, eu conseguia grupo de estudos, né?! Mesmo do mestrado eu conseguia ir nas reuniões, organizava meus horários pra isso. Porque assim, no ano que eu entrei no mestrado, eles acabaram com aquela licença. Até 2013 tinha uma licença pra você fazer o mestrado e a licença era remunerada, você não perdia a lotação na escola. Você se afastava e ficava por conta. No ano que eu entrei acabou essa licença. Acabou esse direito. (Diretora A, Escola EA, maio 2018, grifos nossos) 
O que a diretora $\mathrm{A}$ interpreta como fim de um direito, afinal é previsto no plano de carreira do magistério do estado de Minas Gerais, é visto por outra colega da mesma escola como fim de um privilégio.

Depois eu fiz, passei no mestrado [em] educação em Petrópolis na [nome da instituição], só que naquela época, aí eu já era diretora da escola, naquela época você não tinha, não podia afastar para fazer mestrado, que hoje também, atualmente também não pode, parece que o governo atual, por conta de despesa, teve que cortar esse, digamos, privilégio. (Professora M, Escola EA, maio 2018, grifos nossos)

Se consultarmos o dicionário de língua portuguesa, podemos encontrar como definição de privilégio "vantagem concedida a alguém com exclusão de outros e contra o direito comum" (Bueno, 2007). A fala da professora M, associando a licença remunerada para estudo como um privilégio, exemplifica como discursos podem inculcar no sujeito determinados valores sociais (Fairclough, 2016). Vale ressaltar que essa expressão tem sido muito utilizada pelos meios de comunicação para justificar reformas como a da previdência, que acabariam com os privilégios de determinados setores. Assim, tem se tornado uma palavra muito natural, porém é importante observarmos se o seu uso não indica incompreensão sobre a importância do processo formativo para o trabalho docente.

$\mathrm{Na}$ rede municipal pesquisada, a preocupação está ligada a manter o plano de carreira. Considerado por muitos como bastante avançado, tal plano prevê progressões funcionais por tempo de carreira e por formação, além de licenças remuneradas para aperfeiçoamento profissional, contudo o sindicato e a categoria têm se mobilizado e incluído, nas últimas pautas de greve, a suspensão do que ficou conhecido como artigo $9^{\circ}$.

O referido artigo foi incluído pelo poder executivo municipal, em uma negociação salarial, sem a concordância do sindicato, e permite que sejam concedidos aumentos diferenciados para a categoria. Os reajustes dos salários no início de carreira obedecem aos percentuais estabelecidos pelo governo federal para correção do piso salarial nacional, entretanto os salários dos profissionais que estão em níveis mais altos do plano de carreira são reajustados a partir dos percentuais que o Executivo avaliar como possíveis e necessários. Os críticos a essa medida apontam que o efeito desse ajuste diferenciado é o achatamento, aproximando os salários mais altos do valor mínimo a ser pago, como relatou o vice-diretor $\mathrm{V}$ :

Entrevistado: $\mathrm{E}$ a parte da lei do piso que faz sobre a questão salarial virou uma briga. Por quê? Aqui em Juiz de Fora, a gente tem o artigo nono. Artigo nono? Que é um artigo que permitiu.

Entrevistadora: Eu acho que é o nono.

Entrevistado: Que permitiu à [Secretaria de Recursos Humanos] SRH, administrativo da prefeitura, diferenciar os aumentos dos funcionários. Então o que ele fez? Vamos supor, é, o contratado que tem o salário muito baixo, vamos su- 
por, 1.200 reais, se na lei do piso o aumento dos professores foi de $8 \%$, esse cara tem que ganhar [...], porque o artigo nono, ele não permite, dá diferenciados. Então ele dá 8\%, e pra um cara como eu, que tem o salário base de 2 mil, ganho $4 \%$. Então o que você tem? Você tem o achatamento da categoria. (Vice-diretor V, Escola MJ, set. 2018)

Apesar de a lei do piso e de o plano de carreira envolverem tantas questões, as informações obtidas com os participantes desta pesquisa indicam que os docentes pouco discutem coletivamente tais temas. Existem algumas conversas na sala dos professores, nos horários de intervalo, conforme relatos, porém muitas vezes acabam tornando-se momentos para desabafos, assim como a professora $\mathrm{L}$ expressou ao tratar das reuniões na escola:

O que eu percebo é que os professores ou falam..., ou... Ou é um momento pra falar da sua vida, o que fez no dia ou algum caso ou algo diferente que aconteceu, ou é um momento de falar da..., dos problemas. Assim, infelizmente, vira às vezes, é até uma sessão meio de terapia: "Ah, a turma tal, o aluno assim, hoje eu passei isso, não sei o quê, o fulano e tal”. Então é mais assim, é algum mais assim das turmas mesmo que eu percebo assim. (Professora L, Escola EA, maio 2018)

Além da lei do piso e do plano de carreira, a reforma do ensino médio foi indicada como uma das políticas educacionais mais discutidas na escola.

\section{A REFORMA DO ENSINO MÉDIO}

Como tratado anteriormente, a chamada reforma do ensino médio, aprovada em 2017, aconteceu de forma bastante abrupta, por meio de uma MP, provocando inúmeras críticas e movimentos de ocupação por alunos dos prédios de escolas públicas (Rossi, 2016). Tal situação despertou a necessidade de o governo federal investir maciçamente em publicidade, no sentido de convencer a população sobre a importância e os benefícios de tal medida. Para isso, além de contar com os meios tradicionais de comunicação, como TV e rádio, o governo utilizou também youtubers, como denunciado por um jornal (Portinari e Saldaña, 2017), para inserirem na internet comentários positivos à reforma.

Essa pode ser uma das possíveis explicações para o tema estar entre os mais discutidos nas escolas, considerando que apenas as instituições estaduais oferecem o ensino médio, entretanto é importante ponderar que, mesmo tendo correspondido a $57,5 \%$ da frequência de escolha para o item 3.5 do questionário - "Quais das atuais políticas educacionais têm sido alvo de discussões na escola?” - , não consta das atas de reuniões registro das discussões sobre a reforma, e o tema aparece apenas timidamente na fala de dois dos entrevistados.

$\mathrm{O}$ vice-diretor $\mathrm{V}$, que atua em uma escola municipal, ao falar sobre qualidade na educação, faz referência à reforma do ensino médio, criticando o fato de ser possível a atuação do profissional de notório saber, o que, em sua opinião, não resolve o problema da qualidade e, ainda, representa desvalorização docente. 
Aí, o governo, pra tampar com a peneira, cria o notório saber, que aí vão dar aula disso. Aí, ao invés de ele vir e investir no profissional de educação, ele busca profissionais de outra área pra poder cumprir demanda. Mas aí deixa o professor na mesma situação ruim que estava. (Vice-diretor V, Escola MJ, set. 2018)

A professora $\mathrm{P}$, que atua em uma escola estadual, é a única a fazer referência explícita à reforma do ensino médio como uma das políticas que têm chamado sua atenção. Afirmou compreender que tal reforma está ligada à BNCC e tem preocupação quanto a seus efeitos.

Entrevistada: Pois é, eu acho que uma coisa está ligada à outra. Porque, porque eu acho assim, adolescente é muito novo para ele fazer escolhas, entendeu? Pra ele, pra ele... Eu falo por mim, eu lembro que, quando eu terminei o ensino médio, eu fiquei naquela dúvida, que eu não sei o que eu vou fazer e tal... E como é que no ensino médio você vai fazer escolhas daquilo que você quer? Matéria que você quer... Tem muito adolescente que não sabe o que quer lá na frente.

Entrevistadora: Não tem nem assim um suporte teórico pra...

Entrevistada: Não tem pra fazer essas escolhas, então eu acho muito complicado, eu acho que isso vai ser bem prejudicial. (Professora P, Escola EH, ago. 2018)

Apesar de manifestar sua preocupação, a professora $\mathrm{P}$, na continuidade da entrevista, deixou claro que não havia, na escola, momentos para discussão desses temas: "Não tem nenbum momento pra gente discutir, não. É assim, em conversa de intervalos" (Professora P, Escola EH, ago. 2018). Tal afirmação reforça nossa percepção da pouca ou da não existência de discussões sobre as políticas educacionais no interior das escolas, assunto de que tratamos a seguir.

\section{A DISCUSSÃO SOBRE POLÍTICAS EDUCACIONAIS}

No questionário, as reuniões pedagógicas foram apontadas como o momento no qual se discutem questões relacionadas às políticas educacionais $(78,8 \%)$, porém, quando se questionaram os entrevistados sobre os assuntos mais discutidos nas reuniões pedagógicas (questão 3.11), as respostas mais frequentes foram: ações pedagógicas (30\%) e organização interna $(30,2 \%)^{7}$. Para esclarecer esse ponto, buscamos, nas leituras de atas e nas entrevistas, informações que acabaram por revelar a inexistência de debates mais aprofundados.

As entrevistas indicaram que, para alguns professores, como $\mathrm{T}$, as discussões sobre políticas não acontecem:

Entrevistadora: Então, além do tema da inclusão, outro tema surge?

7 Cabe esclarecer que essa era uma questão aberta e as respostas foram agrupadas nessas categorias. Consideramos ações pedagógicas as relativas a questões como projeto político-pedagógico, processos avaliativos, projetos de aprendizagem, entre outros; e como organização interna, assuntos como passeios, eventos, organizações do espaço. 
Entrevistada: Sobre políticas?

Entrevistadora: É.

Entrevistada: Até o momento ainda..., não.

Entrevistadora: E, nas reuniões pedagógicas, até onde você tem conversado? Quais são os temas que eles mais tratam nessas reuniões? [...]

Entrevistada: Conteúdo. No sexto ano é conteúdo. Professores desabafando sobre disciplina. Sobre a dificuldade de trabalhar com alguns alunos. Isso do sexto ao nono. Fica basicamente quatro horas, porque são vários professores, então fica mais ou menos baseado nisso. Do segundo ao quinto, sobre alfabetização. $\mathrm{E}$ aí, às vezes, professores de quarto e quinto anos reclamando dos alunos que passaram e que tão com defasagem. (Professora T, Escola EH, ago. 2018)

Para essa professora, a discussão de conteúdo não tem ligação com as políticas educacionais ou mesmo tem acontecido na escola, como se assim fosse possível. Lembrando Freire (1996), não há como o ser humano estar no mundo de maneira neutra. $\mathrm{O}$ espaço pedagógico, "neutro por excelência, é aquele em que se treinam os alunos para práticas apolíticas” (Freire, 1996, p. 110), o que para o autor não é possível e é reacionário.

Todavia, o depoimento da coordenadora dessa mesma escola ajuda-nos a entender a afirmação da professora T. Ao justificar o porquê de os momentos de discussão sobre políticas educacionais serem raros, ela revela:

Porque uma vez ao mês muito pouco, e aí a gente ainda disputa essas quatro horas com a direção, pra dar aqueles avisos gerais, com lanche, então sobra para gente pouco tempo e o professor ainda tem a opção de escolha. Se ele trabalha em outro lugar, se ele tem dois cargos, ele pode escolher se ele vai na opção 1 , que acontece no sábado, ou na opção 2, que acontece durante a semana. (Coordenadora G, Escola EH, set. 2018)

A falta de tempo, a sobrecarga de atividades e a dificuldade de encontrar momentos para reunir o coletivo parecem inibir as discussões sobre as políticas educacionais na escola, como declara o diretor da Escola EH (set. 2018): "A sobrecarga é muito grande, fica muito bitolado, assim dizer, na rotina da escola”.

Os depoimentos indicam sobrecarga, fruto do aumento de demandas nas escolas, sobretudo ligadas a questões sociais e a um tensionamento do tempo, especialmente nas escolas municipais. Nessa rede de ensino, a reorganização do tempo foi feita de forma que as horas dedicadas ao extraclasse não são necessariamente cumpridas na escola. Assim, muitos profissionais relutam em estar na instituição além do tempo da docência, o que exige da direção esforços para a organização de tempos coletivos e, ainda, resulta em uma intensificação no horário de atividades realizadas dentro da escola, como revelado na fala do vice-diretor $\mathrm{V}$ (Escola MJ, set. 2018): "Agora, imagina um coordenador da prefeitura, ele faz 14 horas e 40 minutos por 
semana. Ai, vamos supor, a coordenadora pedagógica da tarde são três tardes cheias e uma tarde meada. Em uma tarde cheia você acha que dá conta de fazer isso? Por isso não dâ".

$\mathrm{Na}$ rede municipal pesquisada, além dos docentes, os coordenadores pedagógicos e diretores têm $1 / 3$ de sua carga horária destinada a atividades extraclasse, em observância ao disposto na chamada lei do piso, porém a redução da carga horária de coordenadores e diretores não resultou em contratação de novos profissionais. As atividades que seriam desenvolvidas pelo coordenador em cinco dias da semana devem ser concentradas agora em três dias e meio, ou não são concluídas. Por isso, o vice-diretor afirma: "Não dá!" (Vice-diretor V, Escola MJ, set. 2018).

Não podemos desconsiderar que a sobrecarga também está ligada ao fato de os professores terem de se desdobrar em vários cargos, em razão dos baixos salários, como revela o desabafo da professora M (Escola EA, maio 2018): "A gente podia ganhar um dinheiro melhor em um cargo só, que aí não precisava da gente ficar nessa correria e se dedicava mais".

A professora $\mathrm{M}$ trouxe outro elemento para entendermos a pouca discussão sobre políticas educacionais na escola, além da questão da falta de tempo. Conforme entrevista, ela procura não entrar nessas discussões, "porque a postura política às vezes acaba atrapalhando na amizade, então eu procuro evitar" (Professora M, Escola EA, maio 2018).

Paro (1997), ao tratar dos condicionantes que interferem no processo de participação, sinalizou, entre outros, os condicionantes ideológicos, que, nesse caso, podem ser ilustrados pela fala dessa professora, a qual acredita que a discussão sobre políticas educacionais, ao expor diferentes posturas, compromete as relações interpessoais. Tal afirmação pode revelar o fortalecimento do discurso de setores mais conservadores da sociedade, que, como tratado no início deste texto, querem retirar da escola discussões e temas que consideram desnecessários à imagem que vem sendo construída do professor como um técnico.

Ball (2008) aponta a importância de se analisar os níveis macro e o micro quando se pesquisam políticas educacionais. Acreditamos que tal relação também deve se fazer presente quando professores, na escola, discutem sobre seu trabalho, afinal é esse o contexto da prática, em que as políticas se materializam, mas também é onde pode ser iniciado o movimento de elaboração de novas políticas. Entretanto, depoimentos como o da professora $\mathrm{L}$ indicam que esse movimento não tem acontecido: "Num nivel macro, eu confesso que eu nunca participei aqui na escola mesmo e nem na outra que eu trabalhei o ano passado" (Professora L, Escola EA, maio 2018). E por que isso acontece?

Para tentarmos entender o porquê, é preciso primeiramente considerar como as questões sobre política chegam à escola. Conforme respostas ao questionário, os responsáveis por levar esses assuntos para a escola são: a direção (66,3\%), o sindicato $(50 \%)$, os colegas $(46,3 \%)$ e a mídia $(43,8 \%)^{8}$. Considerando ainda que $72,5 \%$ dos respondentes afirmaram não participar de discussões políticas em outros espaços

8 É necessário considerar que os respondentes poderiam escolher mais de uma alternativa. Portanto, os percentuais apresentados revelam a frequência de escolha da alternativa. 
além da escola, podemos afirmar que temos motivos para nos preocupar sobre como tais discussões têm acontecido. Afinal, segundo Fairclough (2016), os textos, como uma dimensão do discurso, são consumidos de acordo com os recursos de interpretação do indivíduo ou, ainda, seu próprio contexto, o que pode resultar em intérpretes mais submissos, por se "ajustarem as posições que são estabelecidas para eles nos textos" (Fairclough, 2016, p. 180), ou mais resistentes.

As entrevistas revelaram diretores sobrecarregados, com dificuldades de organizar os momentos coletivos, terem tempo para investirem em sua formação e se manterem atualizados sobre diferentes temas. Os depoimentos indicaram que seu conhecimento acerca de determinado assunto se dá por interesse particular, daí superando diversas dificuldades ou pelo que as Secretarias de Educação apontam como demandas, conforme ilustrado no depoimento da diretora $\mathrm{A}$ :

Entrevistadora: E em que momento o pessoal discute, por exemplo, as questões de "ah, a política que está sendo implementada"?

Entrevistada: Geralmente na reunião de módulo coletivo, muito também direcionado quando tem alguma coisa da superintendência pra passar, a gente direciona. (Diretora A, Escola EA, maio 2018)

Além de as pautas das reuniões poderem ser definidas não de uma demanda da escola, mas do órgão central, a forma como as informações são repassadas também merecem nossa atenção. $\mathrm{O}$ relato do vice-diretor $\mathrm{V}$ sobre as discussões da $\mathrm{BNCC}$ traz importantes elementos:

Entrevistadora: $\mathrm{Na}$ escola você falou que teve alguma discussão.

Entrevistado: Sim, mas muito rasa, tá?! Muito rasa.

Entrevistadora: Mas você que propôs.

Entrevistado: É quase que de explanação. “Ó, essa é a base, baseada em competência... O que é competência?”. (Vice-diretor V, Escola MJ, set. 2018)

Talvez seja uma das explicações para a BNCC não aparecer entre os assuntos mais discutidos na escola, e, quando questionados diretamente sobre o tema, apenas $26 \%$ dos respondentes ao questionário afirmaram que as questões sobre a BNCC foram abordadas. As respostas indicam ainda uma discussão muito superficial: leitura da introdução, exibição de vídeo etc.

Se a discussão promovida pela direção, muitas vezes, é orientada pelas demandas dos órgãos centrais e acontecem de forma superficial, a promovida pelo sindicato também tem limitações.

Diante do contexto nacional de reformas trabalhistas, previdenciárias etc., os sindicatos têm reunido suas forças para o enfrentamento de tais reformas, sobretudo daquilo que representa ataque aos direitos dos trabalhadores. Daí, contam com professores que atuam no sindicato para levar notícias às escolas, o que acaba acontecendo nos horários de intervalo e recreio, pois, como dissemos anteriormente, 
o tempo para discussões na escola é restrito. Além disso, nem sempre as relações entre as notícias trazidas pelos representantes do sindicato e as questões do trabalho cotidiano docente são claramente estabelecidas, ocasionando, muitas vezes, acusações, tais como: "Você tem um sindicato que, ao invés de ir na parte pedagógica, ele é mais politizado" (Vice-diretor V, Escola MJ, set. 18).

Assim, os sindicatos têm enfrentado não só a luta contra o arrocho salarial e a perda de direitos, mas também críticas de sua própria categoria e forte campanha pelas mídias, que buscam fortalecer a imagem do sindicato como uma instituição que suga os trabalhadores e não garante a eles nenhum benefício'.

A outra personagem apontada como responsável por informar os professores sobre as políticas educacionais, a mídia, conta com diversas formas de atuação, tais como a TV, o rádio, o jornal impresso e a internet. Esta última é apontada, nas entrevistas, como forte presença: "Eu acho que eu acompanho tudo. Eu me informo pela internet”(Vice-diretor V, Escola MJ, set. 2018).

Entrevistadora: Como você se informa sobre elas [sobre políticas educacionais]?

Entrevistada: Algumas coisas a gente informa até aqui. Bate-papo de sala de..., intervalo de professor, algumas coisas através de internet, muito, muito através de internet... Pouco assim você vendo. Então, é mais através da internet e grupos também de professores sempre está postando alguma coisa assim... (Professora P, Escola EH, ago. 2018, grifos nossos)

A professora T esclarece o que são os grupos de professores e sua função: “Os professores têm também um grupo pra poder conversar às vezes, no WhatsApp, e passar informação" (Professora T, Escola MJ, set. 2018).

Os professores revelam, então, se informarem sobre as políticas educacionais por meio da internet, de grupos para troca de mensagens. Esse fato merece nossa atenção, principalmente quando consideramos as denúncias de que, nas últimas eleições, aplicativos como esses foram "verdadeiras armas" (Borges, 2018), influenciando até mesmo os resultados, mediante o que ficou conhecido como fake nerws.

Essa situação contribui para que as discussões na escola sobre tais temas sejam muito superficiais, ou, como disse o vice-diretor V (Escola MJ, set. 2018), "muitas vezes as discussões são baseadas no senso comum, na vivência do professor". Tal declaração traz-nos inquietações, afinal, como alertou Fairclough (2016), a utilização de certos vocábulos, aliados ao gênero publicitário, podem contribuir para que determinados discursos se naturalizem, se tornem senso comum e, consequentemente, contribuam para o fortalecimento de certas identidades sociais.

Nas próprias entrevistas, identificamos expressões e argumentos que nos fazem acreditar que a tendência classificada por Fairclough (2016) como comoditização, na qual instituições não criadas para produzir mercadorias passam a se organizar como se assim fossem, esteja se naturalizando nas escolas.

9 O mais recente enfrentamento é a MP no 873/2019, que dificulta o financiamento sindical, estabelecendo que as contribuições sindicais passariam a acontecer via boleto. 
Podemos exemplificar essa naturalização quando a coordenadora $\mathrm{G}$, ao justificar o motivo de seus filhos não terem estudado em escola pública, afirma: "Então eu queria muito ter tido a oportunidade de manter meus filhos na escola pública, mas pra isso eles teriam que ter tido acesso, permanência e sucesso garantido. Infelizmente, hoje, acesso garantido, os outros itens não" (Coordenadora G, Escola MJ, set. 2018, grifos nossos).

A expressão "sucesso", muito ligada a um contexto empresarial e de desempenho, é utilizada no sentido de aprendizagem. Assim, não basta aprender, é preciso ter êxito em uma sociedade que, cada vez mais, se divide entre bem e malsucedidos. Outras expressões do contexto empresarial parecem ter sido incorporadas, tais como a ideia de "vestir a camisa da empresa" e se preocupar com a "concorrência", como verificado em trechos da fala do diretor $\mathrm{B}$, ao tratar do bom resultado do Ideb nos anos iniciais e da influência da greve no aprendizado dos alunos:

Entrevistado: Então, do primeiro ao quinto ano acho que existe um desempenho maior por parte dos professores. Sem dúvida nenhuma, elas vestem mais a camisa. [...] 50 dias de paralisação e greve.E aí como vamos ter qualidade nisso? Com que... já que a concorrência está posta. (Diretor B, Escola EH, ago. 2018, grifos nossos)

A comoditização do discurso educacional provoca a socialização com base em valores da cultura empresarial, na qual o outro passa a ser um concorrente. Além disso, ideias ligadas à remodelagem do serviço público aos padrões do mercado parecem estar enfrentando menor resistência. Na rede estadual, para participarem do processo de eleição de diretores, é necessário que os candidatos se submetam a uma prova de certificação. Ao tratar sobre tal processo, a diretora $\mathrm{A}$, além de elogiar a prova, manifestou simpatia à ideia de que a prova possa ser incorporada ao plano de carreira: "Parece que eles estão pedindo pra que isso seja incluido em um plano de carreira, sabe?! Então a gente faz pra poder participar e ter algum beneficio pra frente" (Diretora A, Escola EA, maio 2018).

Tal proposta poderia vincular promoção a desempenho mensurável por intermédio de provas. A menor resistência a ideias vinculadas a uma lógica de mercado pode ainda favorecer a expansão de discursos privatistas e conservadores. $\mathrm{O}$ vice-diretor $\mathrm{V}$, diante das dificuldades de condições que permitam a qualidade da educação pública, afirma: "Educação pública não presta. A não ser que seja um curso seletista [...]. A não ser como o colégio militar é"(Vice-diretor V, Escola MJ, set. 2018).

A preocupação com as condições oferecidas na escola pública faz com que o vice-diretor acredite que a qualidade esteja no serviço privado ou aconteça apenas para grupos selecionados. Tal crença pode comprometer a defesa da necessidade de superação dos problemas para que a escola pública que acolha a todos seja de fato democrática, garantindo acesso, permanência e aprendizagem.

\section{O QUE AINDA PODEMOS DIZER?}

As informações obtidas revelaram que os professores da realidade pesquisada não têm discutido coletivamente as atuais políticas educacionais. Tal situação parece estar ligada à sobrecarga e à intensificação do trabalho docente, agravando-se pela forma como o tempo escolar é organizado. 
Quando as discussões acontecem, são no momento de reuniões pedagógicas, porém, por conta da demanda de assuntos a serem tratados, questões macro que interferem na realidade educacional, tais como a criação da BNCC e as políticas de avaliação externa, acabam sendo debatidas por meio de informações rápidas e breves explanações, que normalmente têm ficado a cargo da direção das escolas.

$O$ diretor passa a ser a figura identificada como quem tem acesso às informações e pode repassá-las, mas, por sua vez, em razão da sobrecarga de atividades e de limitações pessoais, enfrenta dificuldades para assumir esse papel.

O sindicato, outro agente responsável por levar as informações sobre políticas educacionais à escola, em um contexto de ataques aos direitos trabalhistas, também enfrenta problemas para assumir essas funções, o que se agrava perante campanhas midiáticas de desvalorização do movimento sindical.

Um dos efeitos construtivos do discurso (Fairclough,2016) é a construção de sistemas de conhecimentos e crenças, daí ser motivo de preocupação a constatação de que os professores têm se informado sobre políticas educacionais via grupos de troca de mensagens, os quais, muitas vezes, contribuem para a disseminação de falsas notícias.

Em um contexto de intensificação do trabalho e de poucos momentos coletivos, nos quais mais acontecem explanações que discussões, os professores podem enfrentar mais dificuldades para destrinchar a coerência interna dos textos e questionar "as posições que são estabelecidas para eles nos textos" (Fairclough, 2016, p. 180).

Todas essas informações reforçam a necessidade de maior aproximação entre universidade e escola, começando pelo retorno dos resultados desta pesquisa. Além disso, é importante o fortalecimento de redes envolvendo diversas instituições, como sindicatos e associações de pesquisa, para a criação de mecanismos de comunicação acessíveis, de fácil compreensão, que possam disputar ou se aliar aos aplicativos já utilizados pelos professores nas escolas, mas de forma a fornecer elementos que superem a superficialidade das discussões e possibilitem leituras e interpretações resistentes, as quais reflitam sobre o processo de comoditização educacional e contribuam para a defesa dos princípios de uma sociedade mais justa, acolhedora e democrática.

\section{REFERÊNCIAS}

BALL, S. J. Profissionalismo, gerencialismo e performatividade. Cadernos de Pesquisa, v. 35, n. 126, p. 539-564, set./dez. 2005. http://dx.doi.org/10.1590/S010015742005000300002

BALL, S. J. Education Reform: A critical and pos-structural approach. BuckinghamFiladélfia: Open University Press, 2008.

BONAMINO, A.; SOUSA, S. Z. Três gerações de avaliação da educação básica no Brasil: interfaces com o currículo da/na escola. Educação e Pesquisa, São Paulo, v. 38, n. 2, p. 373-388, abr./jun. 2012.

BORGES, R. WhatsApp, uma arma eleitoral sem lei. E1 País, 2018. Disponível em: https://brasil.elpais.com/brasil/2018/10/18/tecnologia/1539899403_489473.html. Acesso em: $1^{\circ}$ mar. 2019. 
BRASIL. Presidência da República. Lei no 11.738, de 16 de julho de 2008. Regulamenta a alínea "e" do inciso III do caput do Art. 60 do Ato das Disposições Constitucionais Transitórias, para instituir o piso salarial profissional nacional para os profissionais do magistério público da educação básica. Brasil, 2008.

BUENO, S. Minidicionário da língua portuguesa. São Paulo: FTD, 2007.

CRISTALDO, H. MPF diz que Escola sem Partido é inconstitucional e impede o pluralismo. Agência Brasil, 2016. Disponível em: http://agenciabrasil.ebc.com.br/ educacao/noticia/2016-07/mpf-diz-que-escola-sem-partido-e-insconstitucional-eimpede-o-pluralismo. Acesso em: 20 jul. 2019.

DARDOT,P.; LAVAL, C. A nova razão do mundo: ensaio sobre a sociedade neoliberal. São Paulo: Boitempo, 2016.

FAIRCLOUGH, N. Discurso e mudança social. Brasília: Editora da UnB, 2016.

FREIRE, P. Pedagogia da autonomia: saberes necessários à prática educativa. São Paulo: Paz e Terra, 1996.

HYPOLITO, A. M. Trabalho docente na educação básica no Brasil: as condições de trabalho. In: OLIVEIRA, D. A.; VIEIRA, L. F. (orgs.). Trabalho na educação básica: a condição docente em sete estados brasileiros. Belo Horizonte: Fino Traço, 2012. p. 211-230.

MAINARDES, J. Abordagem ciclo de políticas: uma contribuição para a análise de políticas educacionais. Educação e Sociedade, Campinas, v. 27, n. 94, p. 47-69, jan./ abr. 2006. http://dx.doi.org/10.1590/S0101-73302006000100003

MAPA EDUCACÃO. Entrevista com secretário de Educação Básica Rossieli Soares da Silva. Mapa Educação, 24 set. 2016. Disponível em: http://mapaeducacao.com/ blog/author/mapaeducacao/page/2/. Acesso em: $1^{\circ}$ mar. 2017.

NOCELLI, G. Concurso da Educação da Prefeitura de JF sai no $2^{\circ}$ semestre. Tribuna de Minas, 2018. Disponível em: https://tribunademinas.com.br/noticias/ economia/12-06-2018/concurso-da-educacao-da-prefeitura-de-jf-sai-no-2o-semestre. html. Acesso em: 20 fev. 2019.

PARO, V. H. Gestão democrática da escola pública. São Paulo: Ática, 1997.

PENNA, F. de A. O Escola sem Partido como chave de leitura do fenômeno educacional. In: FRIGOTTO, G. (org.). Escola "sem" Partido: esfinge que ameaça a educação e a sociedade brasileira. Rio de Janeiro: UERJ, LPP, 2017. p. 35-48.

PORTINARI, N.; SALDAÑA, P. Governo paga youtubers para fazer elogios às mudanças do ensino médio. Folha de S.Paulo, 2017. Disponível em: https://www1. folha.uol.com.br/educacao/2017/02/1859532-governo-paga-youtubers-para-fazerelogios-as-mudancas-do-ensino-medio.shtml. Acesso em: 20 fev. 2019.

RAMOS, M. N. Escola sem Partido: a criminalização do trabalho pedagógico. In: FRIGOTTO, G. (org.). Escola "sem" Partido: esfinge que ameaça a educação e a sociedade brasileira. Rio de Janeiro: UERJ, LPP, 2017. p. 75-86.

ROSA, S. S. da. Entrevista com Stephen J. Ball: Privatizações a educação e novas subjetividades - contornos e desdobramentos das políticas (pós) neoliberais. Revista 
Brasileira de Educação, v. 18, n. 53, abr.-jun. 2013. http://dx.doi.org/10.1590/S141324782013000200012

ROSSI,M.PEC 241: com quase 1.000 escolas ocupadas no país, ato de estudantes chega a SP. El País, out. 2016. Disponível em: https://brasil.elpais.com/brasil/2016/10/24/ politica/1477327658_698523.html. Acesso em: 20 jul. 2019.

SEVERINO, A. J. N. Formação de professores e a prática docente: os dilemas contemporâneos. In: PINHO, S. Z. de (org.). Formação de Educadores: dilemas contemporâneos. São Paulo: Editora UNESP, 2011. p. 3-14.

SILVEIRA, Z. S. Onda conservadora: o emergente movimento escola sem partido. In: BATISTA, E. L.; ORSO, P. J.; LUCENA, C. (orgs.). Escola sem partido ou a escola da mordaça e do partido único a serviço do capital. Uberlândia: Navegando Publicações, 2019. p. 17-48.

SINDICATO DOS PROFESSORES DE CAMPINAS E REGIÃO (SINPRO). Desmonte: Conselho Nacional de Educação é entregue a privatistas. 6 jul. 2016. Disponível em: http://www.sinprocampinas.org.br/noticias/noticias/desmonteconselho-nacional-de-educacao-e-entregue-a-privatistas. Acesso em: 18 fev. 2019.

\section{SOBRE A AUTORA}

Elita Betania de Andrade Martins é doutora em educação pela Universidade Federal de Juiz de Fora (UFJF). Professora da mesma instituição. E-mail: elita.martins@uff.edu.br

Recebido em 10 de março de 2019 Aprovado em 27 de agosto de 2019 